\title{
Persistent Depressive Disorder or Dysthymia: An Overview of Assessment and Treatment Approaches
}

\author{
Sherri Melrose \\ Faculty of Health Disciplines, Athabasca University, Athabasca, Canada \\ Email: sherrim@athabascau.ca
}

How to cite this paper: Melrose, S. (2017). Persistent Depressive Disorder or Dysthymia: An Overview of Assessment and Treatment Approaches. Open Journal of Depression, 6, 1-13.

https://doi.org/10.4236/ojd.2017.61001

Received: December 20, 2016

Accepted: January 20, 2017

Published: January 23, 2017

Copyright $\odot 2017$ by author and Scientific Research Publishing Inc. This work is licensed under the Creative Commons Attribution International License (CC BY 4.0).

http://creativecommons.org/licenses/by/4.0/ (c) (i) Open Access

\begin{abstract}
Persistent depressive disorder or dysthymia is a recurrent depressive disorder with no clearly demarcated episodes. Onset is insidious and can occur in adolescence or adulthood. Dysthymia frequently remains unrecognized and undiagnosed for years. Co-morbid major depression, anxiety, personality, somatoform and substance abuse disorders are common. Symptoms center on sad mood, pessimism and hopelessness. Sufferers experience significant functional impairment and are at risk of death by suicide. Those most at risk are female, unmarried, live in high income countries and have family histories of depression. Screening instruments include the Cornell Dysthymia Rating Scale (CDRS). Typical treatments are antidepressant medications and cognitive behavioral analysis system of psychotherapy (CBASP). This paper provides health professionals with an overview of assessment and treatment approaches in dysthymia.
\end{abstract}

\section{Keywords}

Persistent Depressive Disorder, Dysthymia, Chronic Depression, Recurrent Depression, Non-Episodic Depression

\section{Introduction}

Living with the unrelenting burden of persistent depressive disorder (PDD) or dysthymia leaves those who are afflicted feeling despondent and hopeless most of their lives. PDD or dysthymia is a recurrent, prolonged depressive disorder with no clearly demarcated episodes. Dysthymia, from the Greek "ill humor" or "bad state of mind" is understudied, often undertreated and can lead to high rates of death by suicide (Cristancho, Kocsis \& Thase, 2012; Ishizaki \& Mimura, 2011; Niculescu \& Akiskal, 2001). Existing research has focused on diagnosing 
dysthymia and evaluating treatment with antidepressant medication and psychotherapy. Most of this work has been directed to physicians. However, health professionals from a variety of different settings can expect to encounter people struggling to cope with dysthymia in their practice. Raising awareness about dysthymia among all members of health care teams can make an important difference in recognizing the disorder and initiating appropriate referrals. Geared to a multidisciplinary audience, this article presents an explanation of dysthymia by explaining current assessment and treatment approaches.

\section{Assessment}

\subsection{Diagnosis}

The process of diagnosing PDD or dysthymia is not straightforward. For many individuals, a constant battle with low grade depression, sad moods and a lack of excitement has become a way of life. Once known as neurotic depression, in 1980 the diagnosis of dysthymia was introduced into the third edition of the $\mathrm{Di}$ agnostic and Statistical Manual of Mental Disorders, the DSM-111 (American Psychiatric Association, 1980). At that time, the depressive symptoms of dysthymia were characterized as less severe but of longer duration than those of major depressive disorder (MDD). Dysthymia was associated with disturbances in appetite, sleep, energy, concentration, self-esteem and feelings of hopelessness (American Psychiatric Association, 1980).

Later, in 2000, the diagnosis of chronic depressive disorder, where symptoms of depressed mood, loss of interest in daily activities and impaired social, occupational or educational function persisted longer than two years was introduced into the DSM-IV-TR (American Psychiatric Association, 2000). Today, the DSM-5 consolidated the diagnoses of dysthymia and chronic depressive disorder into persistent depressive disorder PDD, often still identified as dysthymia (American Psychiatric Association, 2013).

Dysthymia is diagnosed in adults when individuals have not been free of their depressive symptoms for longer than 2 months over a 2 -year period and have not experienced an episode of major depression or mania. In children and adolescents, the criteria span a 1-year period. However, two key features of dysthymia are first that no clearly demarcated episodes occur and second that the duration is prolonged and can occur both below and above the stipulated 1 or 2-year cut-off points (Uher, 2014). Some people may only seek help after experiencing depressive symptoms for decades rather than just after 2 years (Hellerstein, 2014).

\subsection{Co-Morbidity}

Dysthymia frequently co-occurs with other psychiatric conditions. Many people with dysthymia also develop major depressive disorder MDD, a condition known as double depression (Dunner, 2005; Keller, Hirschfeld, \& Hanks, 1997; Klein, Shankman, \& Rose, 2006). MDD is characterized by depressed mood, loss of interest or pleasure, weight gain or loss, insomnia or hypersomnia, psycho- 
motor agitation or retardation, fatigue, feelings of worthlessness, difficulty concentrating and suicidal ideation most of the day, nearly every day during the same two week period (American Psychiatric Association, 2013). The disorders differ in that the most common symptoms of dysthymia are low self-esteem and pessimism; while the most common symptoms of MDD are neuro-vegetative signs such as sleep or appetite disturbances (Gwirtzman, Blehar, McCullough, Kocsis, \& Prien, 1997). In both MDD and dysthymia, people experience feelings of hopelessness and are unable to find relief from their despair. When double depression is present, these feelings of hopelessness intensify (Joiner, Cook, Hersen, \& Gordon, 2007). Most people with dysthymia develop at least one episode of MDD in their lifetime (Klein, Schwartz, Rose, \& Leader, 2000).

Further, anxiety disorders are often present in children, adolescents (Masi, Millepiedi, Mucci, Pascale, Perugi, \& Akiskal, 2003) and adults (Pini, Cassano, Simonini, Savino, Russo, \& Montgomery, 1997; Sansone \& Sansone, 2009; Shankman \& Klein, 2002) with dysthymia. Given the frequency of co-occurring anxiety and dysthymia, Niculescu and Akiskal proposed a division of dysthymia into two distinct endophenotypes or sub types: anxious dysthymia (formerly known as atypical) and non-anxious or anergic dysthymia (formerly known as typical) (Niculescu \& Akiskal, 2001). Anxious dysthymia is hypothesized as having an association with low serotonin, which regulates mood, calmness and composure when dealing with stressful events. When people with anxious dysthymia perceive stress, their symptoms of insecurity, low self-esteem and restlessness exacerbate or worsen (Niculescu \& Akiskal, 2001).

Non-anxious or anergic dysthymia is hypothesized as having an association with low dopamine, which is involved in motivation, thinking, and motor activities (Niculescu \& Akiskal, 2001). When people with anergic dysthymia perceive they have failed, they are likely to demonstrate more intense manifestations of sluggish reactivity, low drive, low energy and psychomotor inertia. In combination with the extended duration of their depressive illness, this subtyping of symptoms suggests that these traits may have evolved as a way for individuals to cope with the stresses and failures they believe they face (Niculescu \& Akiskal, 2001).

Personality disorders, somatoform disorders, and substance abuse disorders also commonly co-occur with dysthymia (Sansone \& Sansone, 2009). Personality disorders, such as depressive personality disorder, which is characterized by self-critical tendencies, introversion and a gloomy, negative outlook can appear very similar to dysthymia (Ishizaki \& Mimura, 2011). Similarly somataform disorders, which are characterized by physical symptoms that suggest a general medical condition, but are not fully explained by that condition, can overlap with dysthymia (Feder, n.d.). For example, unexplained back pain, headaches and muscle soreness can be associated with both conditions (Feder, n.d.). High levels of alcohol dependence have been associated with dysthymia (Diaz, Horton $\&$ Weiner, 2012). People who develop dysthymia before the age of 21 are predisposed to developing both comorbid personality disorders and substance use 
disorders (Halverson, 2015).

As a non-episodic illness, dysthymia is difficult to recognize (Avrichir \& Elkis, 2002; Weissman \& Klerman, 1977). Health professionals may perceive sufferers as people who demonstrate sarcastic, nihilistic, morose, demanding and plaintive behaviors rather than as people experiencing prolonged and profound sadness (Spanemberg \& Juruena, 2004). Having endured their illness for extended periods of time, people with dysthymia can project pessimism, gloominess and a lack of self-confidence (Akiskal, 1983). Rather than seeking help for a mood disturbance, they may describe feeling generally unwell, lethargic and chronically fatigued (Akiskal, 1996; Brunello, Akiskal, Boyer, Gessa, Howland, Langer et al., 1995). Consequently, adequate assessment of dysthymia may not occur (Spanemberg \& Juruena, 2004). In 2009, Sansone and Sansone described people with dysthymia as forlorn and overlooked a representation that continues to be applicable (Sansone \& Sansone, 2009).

\subsection{Severity}

The chronic nature of dysthymia can cause greater impairment to functioning than acute depression (Sandhu, Ghosh, \& Dellenbaugh, 2016). Dysthymia sufferers are less likely to work full-time, they receive income supplements more often and they are more likely to report interference with social activities as a result of emotional and physical problems (Hellerstein, Agosti, Bosi, \& Black, 2010). For those with co-occurring personality disorders, dysthymia imposes significant additional impairment to their psychosocial functioning (Hellerstein, Skodol, Petkova, Xie, Markowitz et al., 2010)

People with dysthymia have a $71.4 \%$ risk of relapsing into another period of chronic depression (Klein, Shankman, \& Rose, 2006). When suicidal ideation occurs in one episode of depression, it is likely to recur in subsequent episodes (Williams, Crane, Barnhofer, van der Does, \& Segal, 2006). It is important to emphasize that individuals with dysthymia have been found to be more likely to attempt suicide and to be hospitalized than those with major depression (Klein, Schwartz, Rose, \& Leader, 2000). As many as $51 \%$ of individuals being treated for persistent depression continued to experience suicidal ideation after 32 months (Young, Klap, Shoai, \& Wells, 2008). Clearly, when health professionals determine that individuals in their care are experiencing depression, it is critical to assess for suicidal ideation.

\subsection{Prevalence}

Dysthymia, a long term "smouldering mood disturbance" with infrequent and transient periods of normal mood is common in the community, primary care and mental health settings (Sansone \& Sansone, 2009). The disorder has been estimated to affect approximately 1.5 percent of the adult population, with $49.7 \%$ of these cases classified as severe (Kessler, Chiu, Demler, \& Walters, 2005). Only $67.5 \%$ of those with the disorder are receiving treatment and for $27.5 \%$ of those individuals, the treatment is only minimally adequate (Wang, Lane, Olfson, Pin- 
cus, Wells, \& Kessler, 2005). As many as 7\% of primary care patients and 33\% of psychiatric outpatients are believed to be living with dysthymia (Sansone \& Sansone, 2009).

Dysthymia follows a chronic course and can have an early and insidious onset, often in adolescence (Halverson, 2015). In adolescents, approximately 11\% of 13 to 18 year olds experienced major depressive disorder/dysthymia, with $3.3 \%$ of these considered seriously debilitating (Merikangas, He, Burstein, Swanson, Avenevoli, Cui et al., 2010).

\subsection{Etiology}

While the cause of the disorder may not be clear, physiologic abnormalities have been associated with dysthymia. For example, polysomnography or sleep studies have indicated irregularities such as shorter periods of dreamless sleep (nonrapid eye movement NREM sleep); taking a shorter period of time to enter rapid eye-movement REM sleep (latency); and increased frequency of rapid eye movements (density) during REM sleep (Abad \& Guilleminault, 2005). Interleukin-1, a group of 11 cytokines which plays a central role in the regulation of immune and inflammatory responses can be elevated (Anisman, Ravindran, Griffiths, \& Merali, 1999). Further, serotonin, a neurotransmitter, can have a lower maximum rate of uptake (Ravidran, Chudzik, Bialik et al., 1994). In females with dysthymia, platelet monoamine oxidase activity, which is needed for neurotransmissions, can be lower (Tripodianakis, Markianos, Sarantidis, Spyropoulou, Taktikou, \& Bistolaki, 1998).

As has been demonstrated in MDD, increased neural activity, or functional connectivity within the default mode network (DMN) of the brain may be important in the pathophysiology of dysthymia (Posner, Hellerstein, Gat, Mechling, Klahr, Wang et al., 2013). The DMN is a collection of brain regions that are less active during goal-directed behaviors and more active when in a resting state (Posner et al.). When Posner, Hellerstein and colleagues examined the effects of antidepressant medications on dysthymia, they identified that antidepressants normalized DMN connectivity, suggesting a causal pathway (Posner et al.).

Psychosocially, it is possible that severe events in childhood and stressful life events such as the loss of a partner or serious illness may predispose people to dysthymia (Wu, Wang, Wei, Zhang, Shi, Gao et al., 2013). Those with family histories of major depression, bipolar disorder, dysthymia and personality disorders are particularly susceptible (Ishizaki \& Mimura, 2011; Lizardi \& Klein, 2000). Women (Charlson, Ferrari, Flaxman, \& Whiteford, 2013) and unmarried people are at greater risk (Markkula, Suvisaari, Pirkola, Pena, Saarni, \& Suvisaari, 2015). Dysthymia is more prevalent in in high-income countries than in low and middle income countries (Gurege, 2011). Females experiencing dysthymia frequently have a history of thyroid dysfunction (Scott, Baker, \& Eccleston, 1988).

\section{Cornell Dysthymia Rating Scale (CDRS)}

As the previous discussion has illustrated, a significant number of people are 
living with the debilitating effects of dysthymia and are not functioning to their full potential. By screening for the disorder, particularly in familiar primary care settings where people are accustomed to coming for treatment, health professionals can help identify those who are suffering.

The Cornell Dysthymia Rating Scale (CDRS), first developed by Mason and colleagues in 1993 continues to be an efficient screening instrument (Cohen, 1997; Hellerstein, Batchelder, Lee, \& Borisovskaya, 2002; Kannappan \& Bai, 2007; Lam, Michalak \& Swinson, 2005; Mason, Kocsis, Leon, Thompson, Frances et al., 1993). The CDRS is a simple straightforward questionnaire that all members of health care teams can readily implement with the people in their care. The CDRS is a 20-item scale developed specifically to assess frequency and severity of symptoms of dysthymia over the previous week (Mason et al.). Items are scored on a 0 - 4 basis, with a total score range of $0-80$, where higher scores indicate greater severity of symptoms.

The scale can be either self or clinician rated and refers to current and recent symptoms rather than normal premorbid periods, thus making it particularly suitable to assessing the chronic and recurring symptoms of dysthymia (Cohen, 1997). The strength of the CDRS's severity range scores, concurrent validity and content validity indicate it is a valuable instrument (Hellerstein et al., 2002). Additionally, because the CDRS is sensitive to change it can serve as a useful tool for monitoring response to treatment (Lam et al., 2005). The CDRS is freely available in the public domain and no training is required to use the tool.

\section{Treatment Approaches}

\subsection{Pharmacology and Psychotherapy}

Studies have consistently reported the superiority of treating dysthymia with a combined approach of both antidepressant medication and psychotherapy (Jobst, Brakemeier, Buchheim, Caspar, Cuijpers, Ebmeir et al., 2016; Keller, McCullough, Klein, Arnow, Dunner et al., 2000). It is beyond the scope of this article to provide more than a brief explanation of these approaches. Although many groups of health professionals are not directly involved with either medication prescribing and administrating or conducting psychotherapy themselves, having a rudimentary understanding of available treatment can be useful when referring people for the help they need.

In their seminal examination of the treatment of chronic depression, Keller, McCullough, Klein and colleagues randomly assigned patients to one of three treatment groups: a cognitive behavioral-analysis system of psychotherapy (CBASP); administration of the antidepressant nefazodone (serzone); or a combination of the two (Keller, McCullough, Klein, Arnow, Dunner, Gelenberg et al., 2000). While less than half of the patients in the individual groups responded, nearly three-quarters of those in the combined group responded favorably to the combined treatment approach.

The psychotherapeutic approach these researchers implemented, the cognitive behavioral analysis system of psychotherapy (CBASP) was developed specifically 
for people experiencing chronic depression. This approach used a structured, directive "social problem-solving algorithm to address interpersonal difficulties ... [resulting in] patients learn[ing] how their cognitive and behavioral patterns produce and perpetuate their interpersonal problems ... [thereby] remedy[ing] maladaptive patterns of interpersonal behavior (p. 1462). The approach was fully explained in McCullough's 1999 text: Treatment for chronic depression: cognitive behavioral analysis system of psychotherapy (CBASP) (McCullough, 1999). Although the strikingly positive benefits of CBASP were not duplicated in a later study (Kocsis, Gelenberg, Rothbaum, Klien, Trivedi, \& Manber, 2009), this unique type of cognitive behavior therapy, with its focus on the non-episodic nature of dysthymia, continues to be viewed as an important treatment approach (McCullough, Schramm, \& Penberthy, 2015; Negt, Brakemeier, Michalak, Winter, Bleich, Kahl et al., 2016).

In their meta-analysis of research directly comparing the efficacy of psychotherapy and pharmacotherapy in treating depression, Cuijpers and colleagues demonstrated that psychotherapy was more efficacious than pharmacotherapy with tricyclic antidepressants (Cuijpers et al., 2013). On the other hand, Kriston and colleagues' analysis of treatments specifically for persistent depressive indicated that while psychotherapy with medication outperformed medication alone in chronic major depression, it was not more effective in dysthymia (Kriston, Wolff, Westphal, Hölzel, \& Härter, 2014). The benefits of antidepressant medications, which can determined after only a few weeks, can be more rapidly effective that those experienced in therapy sessions, most of which extend over several months (Thase, Friedman, Biggs, Wisniewski, Trivedi, Luther et al., 2007). Yet, intolerance to medications can make therapy a fitting choice for many people. These kinds of conflicting reports illustrate how our understanding of dysthymia as a unique and non-episodic depression is continually evolving.

Straddling both approaches, Uher suggested initiating treatment with medication and then following up with therapy (Uher, 2014). For example, antidepressants with strong efficacy and good tolerability include selective serotonin reuptake inhibitors (SSRIs) such as sertraline/zoloft; monoamine oxidase inhibitors (MAOI) such as moclobemide/manerix or phenelzineis/nardil; or tricyclic antidepressants (TCAs) such as imipramine/tofranil. Once the medications have achieved at least a partial response, then therapy can be individualized to address symptoms associated with depression (Uher, 2014).

\subsection{Alternative Therapies}

Alternative therapies have also been considered in the treatment of dysthymia. St John's wort/hypericum, often viewed by the lay public as an herbal remedy, has been found somewhat effective in minor depression but less so in dysthymia (Randløv, Mehlsen, Thomsen, Hedman, von Fircks et al., 2006). Cautions associated with St. John's wort include potential interactions with blood-thinning drugs, birth control pills, chemotherapy, HIV/AIDS medications and antidepressants (Mayo Clinic, n.d.). 
Likewise, exercise has been found to be beneficial as an adjunct to treatment of depression, but the effects are not well understood in dysthymia (Mead, Morley, Campbell, Greig, McMurdo, \& Lawlor, 2010). Lifestyle modifications, also known as lifestyle medicine, where people adopt healthier patterns of eating, physical activity, relaxation/sleep, substance use and social interaction are believed to improve depression (Sarris, O’Neil, Coulson, Schweitzer, \& Berk, 2014). Professionals from all health disciplines can invite clients in their practice to consider making changes in these areas.

\subsection{Future Directions}

Positive outcomes for treating dysthymia may not be immediate and trying different combinations of medications, therapies and lifestyle modifications may be necessary. Responses to treatment, like symptoms, will vary among individuals. Duration of symptoms, support systems, coping mechanisms and current life circumstances can all impact recovery. However, research continues to offer hope for relief from the debilitating symptoms of dysthymia. Levkovitz and colleagues' meta-analysis of the efficacy of treating dysthymia with antidepressants concluded that antidepressant therapy was significantly more effective than placebo in 17 different studies (Levkovitz, Tedeschini, \& Papakostas, 2011).

Plans to implement a meta-analysis of existing clinical trials which explored the efficacy of CBASP therapy in combination with medication are underway (Furukawa, Schramm, Weitz, Salanti, Efthimiou, Michalak et al., 2016). This upcoming review is framed from a differential therapeutics perspective and will seek individual participant data from each of the trials reviewed, allowing findings to be matched to specific subgroups of patients.

\section{Conclusion}

In summary, this paper provided an overview of persistent depressive disorder or dysthymia, explaining assessment approaches in relation to DSM-5 criteria, symptoms, comorbidity, etiology, severity and prevalence. People with dysthymia experience sad moods and feel pessimistic and hopeless to the extent that they are not able to function. Many are at high risk for death by suicide and health professionals should routinely assess for suicidal ideation.

As a non-episodic, insidious and difficult to recognize disorder, dysthymia can first appear in adolescence and remain untreated for years. Women and those who are unmarried are most at risk. Clinician or self-reported scores on the Cornell Dysthymia Rating Scale (CDRS) can immediately communicate people's views about the severity of their illness.

Living with sadness for extended periods of time can leave people suffering from dysthymia resigned to the idea that things are unlikely to change for them. Antidepressant medications offer some relief. However, cognitive behavioral analysis system of psychotherapy (CBASP) is also emerging as an effective treatment. This paper calls for health professionals to integrate dysthymia assessments and referral processes into their practice. Doing so may begin to instil 
needed hope to the many individuals with dysthymia who are simply enduring rather than enjoying their lives.

\section{References}

Abad, V. C., \& Guilleminault, C. (2005). Sleep and Psychiatry. Dialogues in Clinical Neuroscience, 7, 291-303.

Akiskal, H. S. (1983). Dysthymic Disorder: Psychopathology of Double-Blind Long Term Extension of Several of These Proposed Chronic Depressive Subtypes. American Journal of Psychiatry, 140, 11-20. https://doi.org/10.1176/ajp.140.1.11

Akiskal, H. S. (1996). Dysthymia as a Temperamental Variant of Affective Disorder. European Psychiatry, 11, 117s-22s. https://doi.org/10.1016/0924-9338(96)85185-6

American Psychiatric Association (1980). Diagnostic and Statistical Manual of Mental Disorders (3rd ed.). Washington DC: Author.

American Psychiatric Association (2000). Diagnostic and Statistical Manual of Mental Disorders(4th ed., text rev.). Washington DC: Author.

American Psychiatric Association (2013). Diagnostic and Statistical Manual of Mental Disorders (5th ed.). Washington DC: Author. https://doi.org/10.1176/appi.books.9780890425596

Anisman, H., Ravindran, A., Griffiths, J., \& Merali, Z. (1999). Interleukin-1 Beta Production in Dysthymia Before and After Pharmacotherapy. Biological Psychiatry, 46, 16491655. https://doi.org/10.1016/S0006-3223(99)00211-5

Avrichir, B., \& Elkis, H. (2002). Prevalence and Underrecognition of Dysthymia among Psychiatric Outpatients in São Paulo, Brazil. Journal of Affective Disorder, 69, 193-199. https://doi.org/10.1016/S0165-0327(01)00342-1

Brunello, N., Akiskal, H., Boyer, P., Gessa, G., Howland, R., Langer, S. et al. (1995). Dysthymia: Clinical Picture, Extent of Overlap with Chronic Fatigue Syndrome, Neuropharmacological Considerations, and New Therapeutic Vistas. Journal of Affective Disorders, 52, 275-290. https://doi.org/10.1016/S0165-0327(98)00163-3

Charlson, F., Ferrari, A., Flaxman, A., \& Whiteford, H. (2013). 1. The Epidemiological Modelling of Dysthymia: Application for the Global Burden of Disease Study 2010. Journal of Affective Disorders, 151, 111-120. https://doi.org/10.1016/j.jad.2013.05.060

Cristancho, M., Kocsis, J., \& Thase, M. (2012). Dysthymia Disorder and Other Chronic Depressions. Focus the Journal of Lifelong Learning in Psychiatry, 10, 422-427. https://doi.org/10.1176/appi.focus.10.4.422

Cohen, J. (1997). Assessment and Treatment of Dysthymia: The Development of the Cornell Dysthymia Rating Scale. European Psychiatry, 12, 190-193. https://doi.org/10.1016/S0924-9338(97)89103-1

Cuijpers, P., Sijbrandij, M., Koole, S. L., Andersson, G., Beekman, A. T., \& Reynolds, C. F. (2013). The Efficacy of Psychotherapy and Pharmacotherapy in Treating Depressive and Anxiety Disorders: A Meta-Analysis of Direct Comparisons. World Psychiatry, 12, 137-148. https://doi.org/10.1002/wps.20038

Diaz, N., Horton, E., \& Weiner, M. (2012). Dysthymia, Major Depression, and Double Depression among Individuals Receiving Substance Abuse Treatment. Health, 4, 12291237. https://doi.org/10.4236/health.2012.412181

Dunner, D. (2005). Dysthymia and Double Depression. International Review of Psychiatry, 17, 3-8. https://doi.org/10.1080/09540260500064983

Feder, A. (n.d.) Chapter 3532: Somatization. General Medicine Clinics, Columbia Medical School Ambulatory Syllabus. 
http://www.medicineclinic.org/AmbulatorySyllabus4/NEW\%20somatization.htm

Furukawa, T., Schramm, E., Weitz, E. S., Salanti, G., Efthimiou, O., Michalak, J. et al. (2016). Cognitive-Behavioural Analysis System of Psychotherapy (CBASP), a Drug, or Their Combination: Differential Therapeutics for Persistent Depressive Disorder: A Study Protocol of an Individual Participant Data Network Meta-analysis. BMJ Open, 6, e011769. https://doi.org/10.1136/bmjopen-2016-011769

Gwirtzman, H., Blehar, M., McCullough, J., Kocsis, J., \& Prien, R., (1997). Standardized Assessment of Dysthymia. Report of a National Institute Mental Conference. Psychopharmacological Bulletin, 33, 3-11.

Gurege, O. (2011). Dysthymia in a Cross-cultural Perspective. Current Opinion in Psychiatry, 24, 67-71. https://doi.org/10.1097/YCO.0b013e32834136a5

Halverson, J. (2015). Dysthymic Disorder: Background, Etiology, Epidemiology. Medscape. http://emedicine.medscape.com/article/290686-overview

Hellerstein, D., Batchelder, S., Lee, A., \& Borisovskaya, M. (2002). Rating Dysthymia: An Assessment of the Construct and Content Validity of the Cornell Dysthymia Rating Scale. Journal of Affective Disorders, 71, 85-96. https://doi.org/10.1016/S0165-0327(01)00371-8

Hellerstein, D., Agosti, V., Bosi, M., \& Black, S. (2010). Impairment in Psychosocial Functioning Associated with Dysthymic Disorder in the NESARC Study. Journal of Affective Disorders, 127, 84-88. https://doi.org/10.1016/j.jad.2010.04.013

Hellerstein, D. J., Skodol, A. E., Petkova, E., Xie, H., Markowitz, J. C., Yen, S., McGlashan, T. H. et al. (2010). The Impact of Comorbid Dysthymic Disorder on Outcome in Personality Disorders. Comprehensive Psychiatry, 51, 449-457.

https://doi.org/10.1016/j.comppsych.2009.11.002

Hellerstein, D. (2014). Dysthymic Disorder (Persistent Depressive Disorder). Encyclopedia of Psychopharmacology, Berlin: Springer.

Ishizaki, J., \& Mimura, M. (2011). Dysthymia and Apathy: Diagnosis and Treatment. Depression Research and Treatment, 2011, Article ID: 893905.

Jobst, A., Brakemeier, E., Buchheim, A., Caspar, F., Cuijpers, P., Ebmeier, K. et al. (2016). European Psychiatric Association Guidance on Psychotherapy in Chronic Depression across Europe. European Psychiatry, 33, 18-36.

https://doi.org/10.1016/j.eurpsy.2015.12.003

Joiner, T., Cook, J., Hersen, M., \& Gordon, K. (2007). Double Depression in Older Adult Psychiatric Outpatients: Hopelessness as a Defining Feature. Journal of Affective Disorders, 101, 235-238. https://doi.org/10.1016/j.jad.2005.03.019

Kannappan, R., \& Bai, R. (2007). Cognitive Behaviour Therapy as an Adjunct to Drug Therapy in the Treatment of Dysthymic Disorder. Journal of the Indian Academy of Applied Psychology, 33, 195-200.

Keller, M., Hirschfeld, R., \& Hanks, D. (1997) Double Depression: A Distinctive Subtype of Unipolar Depression. Journal of Affective Disorders, 45, 65-73.

https://doi.org/10.1016/S0165-0327(97)00060-8

Keller, M., McCullough, J., Klein, D., Arnow, B., Dunner, D., Gelenberg, A. et al. (2000). A Comparison of Nefazodone, the Cognitive Behavioral-Analysis System of Psychotherapy, and Their Combination for the Treatment of Chronic Depression. New England Journal of Medicine, 342, 1462-1470. https://doi.org/10.1056/NEJM200005183422001

Kessler, R., Chiu, W., Demler, O., \& Walters, E. (2005). Prevalence, Severity, and Comorbidity of Twelve-Month DSM-IV Disorders in the National Comorbidity Survey Replication (NCS-R). Archives of General Psychiatry, 62, 617-627. 
https://doi.org/10.1001/archpsyc.62.6.617

Klein, D., Schwartz, J., Rose, S., \& Leader, J. (2000). Five-Year Course and Outcome of Dysthymic Disorder: A Prospective, Naturalistic Follow-Up Study. American Journal of Psychiatry, 157, 931-939. https://doi.org/10.1176/appi.ajp.157.6.931

Klein, D., Shankman, S., \& Rose, S. (2006). Ten-Year Prospective Follow-Up Study of the Naturalistic Course of Dysthymic Disorder and Double Depression. American Journal of Psychiatry, 163, 872-880. https://doi.org/10.1176/ajp.2006.163.5.872

Kocsis, J., Gelenberg, A., Rothbaum, B., Klien, D., Trivedi, M., Manber, R. et al. (2009). Cognitive Behavioral Analysis System of Psychotherapy and Brief Supportive Psychotherapy for Augmentation of Antidepressant Nonresponse in Chronic Depression: The REVAMP Trial. Archives of General Psychiatry, 66, 1178-1188. https://doi.org/10.1001/archgenpsychiatry.2009.144

Kriston, L., Wolff, A., Westphal, A., Hölzel, L., \& Härter, M. (2014). Efficacy and Acceptability of Acute Treatments for Persistent Depressive Disorder: A Network MetaAnalysis. Depression and Anxiety, 31, 621-630. https://doi.org/10.1002/da.22236

Lam, R., Michalak, E., \& Swinson, R. (2005). Assessment Scales in Depression, Mania and Anxiety. London: Taylor and Francis. http://files3.moshaverfa.com/en/pdf/Assessment/2005_-_Assessment_scales_in_depres sion,_mania_and_anxiety_-_Lam,_Michalak,_Swinson.pdf

Levkovitz, Y., Tedeschini, E., \& Papakostas, G. (2011). Efficacy of Antidepressants for Dysthymia: A Meta-Analysis of Placebo-Controlled Randomized Trials. Journal of Clinical Psychiatry, 72, 509-514. https://doi.org/10.4088/JCP.09m05949blu

Lizardi, H., \& Klein, D. (2000). Parental Psychopathology and Reports of the Childhood Home Environment in Adults with Early-Onset Dysthymic Disorder. Journal of Nervous and Mental Disease, 188, 63-70. https://doi.org/10.1097/00005053-200002000-00001

Markkula, N., Suvisaari, J., Pirkola, S., Pena, S., Saarni, S., \& Suvisaari, J. (2015). Prevalence and Correlates of Major Depressive Disorder and Dysthymia in an Eleven-Year Follow-Up-Results from the Finnish Health 2011 Survey. Journal of Affective Disorders, 173, 73-80. https://doi.org/10.1016/j.jad.2014.10.015

Masi, G., Millepiedi, S., Mucci, M., Pascale, R. R., Perugi, G., \& Akiskal, H. S. (2003). Phenomenology and Comorbidity of Dysthymic Disorder in 100 Consecutively Referred Children and Adolescents: Beyond DSM-IV. Canadian Journal of Psychiatry, 48, 99-105.

Mason, B., Kocsis, J., Leon, A., Thompson, S., Frances, A., Morgan, R. et al. (1993). Measurement of Severity and Treatment Response in Dysthymia. Psychiatric Annals, 23, 625-631. https://doi.org/10.3928/0048-5713-19931101-09

Mayo Clinic (n.d.). Persistent Depressive Disorder (Dysthymia). Alternative Medicine. http://www.mayoclinic.org/diseases-conditions/persistent-depressive-disorder/diagnos is-treatment/treatment/txc-20166621

McCullough, J. (1999). Treatment for Chronic Depression: Cognitive Behavioural Analysis System of Psychotherapy (CBASP). New York: Guilford Publications.

McCullough, J., Schramm, E., \& Penberthy, K. (2015). CBASP: A Distinctive Treatment for Persistent Depressive Disorder. New York: Routledge.

Mead, G., Morley, W., Campbell, P., Greig, C., McMurdo, M., \& Lawlor, D. (2010). Exercise for Depression. Cochrane Database of Systematic Reviews, CD004366.

Merikangas, K., He, J., Burstein, M., Swanson, S., Avenevoli, Cui, L. et al. (2010). Lifetime Prevalence of Mental Disorders in US Adolescents: Results from the National Comorbidity Study-Adolescent Supplement (NCS-A). Journal of the American Academy of 
Child Adolescent Psychiatry, 49, 980-989. https://doi.org/10.1016/j.jaac.2010.05.017

Negt, P., Brakemeier, E., Michalak, J., Winter, L., Bleich, S., \& Kahl, K. (2016). The Treatment of Chronic Depression with Cognitive Behavioral Analysis System of Psychotherapy: A Systematic Review and Meta-Analysis of Randomized-Controlled Clinical Trials. Brain and Behavior, 6, e00486. https://doi.org/10.1002/brb3.486

Niculescu, A., \& Akiskal, H. (2001). Proposed Endophenotypes of Dysthymia: Evolutionary, Clinical and Pharmacogenomic Considerations. Molecular Psychiatry, 6, 363-366. https://doi.org/10.1038/sj.mp.4000906

Pini, S., Cassano, G., Simonini, E., Savino, M., Russo, A., \& Montgomery, S. (1997). Prevalence of Anxiety Disorders Comorbidity in Bipolar Depression, Unipolar Depression and Dysthymia. Journal of Affective Disorders, 42, 145-153. https://doi.org/10.1016/S0165-0327(96)01405-X

Posner, J., Hellerstein, D., Gat, I., Mechling, A., Klahr, K., Wang, Z. et al. (2013). Antidepressants Normalize the Default Mode Network in Patients With Dysthymia. JAMA Psychiatry, 70, 373-371. https://doi.org/10.1001/jamapsychiatry.2013.455

Randløv, C., Mehlsen, J., Thomsen, C., Hedman, C., von Fircks, H. et al. (2006). The Efficacy of St. John's Wort in Patients with Minor Depressive Symptoms or Dysthymia-A Double-Blind Placebo-Controlled Study. Phytomedicine, 13, 215-221.

https://doi.org/10.1016/j.phymed.2005.11.006

Ravidran, A., Chudzik, J., \& Bialik R. (1994). Platelet Serotonin Measures in Primary Dysthymia. American Journal of Psychiatry, 151, 1369-1371.

https://doi.org/10.1176/ajp.151.9.1369

Sandhu, R., Ghosh, S., \& Dellenbaugh, T. (2016). Association between Dysthymic Disability and Disability, with Religiosity as Moderator. Activitas Nervosa Superior, 58, 13-19.

Sansone, R., \& Sansone, L. (2009). Dysthymic Disorder: Forlorn and Overlooked. Psychiatry, 6, 46-51. https://www.ncbi.nlm.nih.gov/pmc/articles/PMC2719439/

Sarris, J., O’Neil, A., Coulson, C. E., Schweitzer, I., \& Berk, M. (2014). Lifestyle Medicine for Depression. BMC Psychiatry, 14, 107. https://doi.org/10.1186/1471-244X-14-107

Scott, J., Baker, W., \& Eccleston, D. (1988). The Newcastle Chronic Depression Study. Patient Characteristics and Factors Associated with Chronicity. British Journal of Psychiatry, 152, 28-33. https://doi.org/10.1192/bjp.152.1.28

Shankman, S., \& Klein, D. (2002). The Impact of Comorbid Anxiety Disorders on the Course of Dysthymic Disorder: A 5-Year Prospective Longitudinal Study. Journal of Affective Disorders, 70, 211-217. https://doi.org/10.1016/S0165-0327(01)00302-0

Spanemberg, L., \& Juruena, M. (2004). Dysthymia: Historical/Nosological Characteristics and Its Relationship with Major Depressive Disorder. Revista de Psiquiatria do Rio Grande do Sul, 26, 300-301.

http://www.scielo.br/scielo.php?pid=S0101-81082004000300007\&script=sci_arttext\&tl $\underline{\mathrm{ng}=\mathrm{en}}$

Thase, M., Friedman, E., Biggs, M., Wisniewski, S., Trivedi, M., Luher, J. et al (2007). Cognitive Therapy versus Medication in Augmentation and Switch Strategies as Second-step Treatments: A STAR ${ }^{\star D}$ Report. American Journal of Psychiatry, 164, 739752. https://doi.org/10.1176/ajp.2007.164.5.739

Tripodianakis, J., Markianos, M., Sarantidis, D., Spyropoulou, G., Taktikou, V., \& Bistolaki, E. (1998). Platelet MAO Activity in Patients with Dysthymic Disorder. Psychiatry Research, 78, 173-178. https://doi.org/10.1016/S0165-1781(98)00011-0

Uher, R. (2014). Persistent Depressive Disorder, Dysthymia, and Chronic Depression: Update on Diagnosis, Treatment. Psychiatric Times, 31, 46. 
http://www.psychiatrictimes.com/special-reports/persistent-depressive-disorder-dysth ymia-and-chronic-depression

Weissman, M.M., \& Klerman, G.L. (1977). The Chronic Depressive in the Community: Unrecognized and Poorly Treated. Comprehensive Psychiatry, 18, 523-532. https://doi.org/10.1016/S0010-440X(97)90002-X

Williams, J., Crane, C., Barnhofer, T., van der Does, A., \& Segal, Z. (2006). Recurrence of Suicidal Ideation across Depressive Episodes. Journal of Affective Disorders, 91, 189194. https://doi.org/10.1016/j.jad.2006.01.002

Wang, P., Lane, M., Olfson, M., Pincus, H., Wells, K., \& Kessler, R. (2005). Twelve Month Use of Mental Health Services in the United States. Archives of General Psychiatry, 62, 629-640. https://doi.org/10.1001/archpsyc.62.6.629

Wu, W., Wang, Z., Wei, Y., Zhang, G., Shi, S., Gao, J. et al. (2013) Clinical Features of Patients with Dysthymia in a Large Cohort of Han Chinese Women with Recurrent Major Depression. PLoS ONE, 8, e83490. https://doi.org/10.1371/journal.pone.0083490

Young, A., Klap, R., Shoai, R., \& Wells, K. (2008). Persistent Depression and Anxiety in the United States: Prevalence and Quality of Care. Psychiatric Services, 59, 1391-1398. https://doi.org/10.1176/ps.2008.59.12.1391

Submit or recommend next manuscript to SCIRP and we will provide best service for you:

Accepting pre-submission inquiries through Email, Facebook, LinkedIn, Twitter, etc. A wide selection of journals (inclusive of 9 subjects, more than 200 journals) Providing 24-hour high-quality service User-friendly online submission system Fair and swift peer-review system Efficient typesetting and proofreading procedure Display of the result of downloads and visits, as well as the number of cited articles Maximum dissemination of your research work

Submit your manuscript at: http://papersubmission.scirp.org/

Or contact ojd@scirp.org 